\title{
Numerical simulation of explosive properties of ethylene-air in flameproof enclosure with interconnected structure under pressure piling
}

\author{
Dong $\mathrm{Li}^{1,2, \mathrm{a}^{*}}$, Shijie Dai ${ }^{1, b^{*}}$ and Xue Meng ${ }^{2, \mathrm{c}}$ \\ ${ }^{1}$ School of mechanical engineering, Hebei University of Technology, Tianjin, China \\ ${ }^{2}$ CNOOC Tianjin Chemical Research \& Design Institute Ltd, Tianjin, China
}

\begin{abstract}
In order to investigate explosive properties of ethylene-air premixed gas in flameproof enclosure with interconnected structure under pressure piling, a $161.5 \mathrm{~mm} \times 161.5 \mathrm{~mm} \times 250 \mathrm{~mm}$ cylindrical flameproof enclosure and a $161.5 \mathrm{~mm} \times 161.5 \mathrm{~mm} \times 500 \mathrm{~mm}$ cylindrical flameproof enclosure connected by a partition with a hole (inner diameter of $15 \mathrm{~mm}$ ) were studied. A mathematical model of the fluid dynamics combustion reaction was selected to perform numerical simulations of this structure using the finite volume method. Numerical simulations revealed that under pressure piling, the maximum explosion pressure in Cavity B was significantly higher than that in Cavity A; the maximum rate of explosion pressure rise in Cavity B was significantly higher than that in Cavity A; combustion rate of combustible gas in Cavity B was much higher than that in Cavity A. Results of the study have practical and theoretical significance for the design and installation of flameproof enclosures.
\end{abstract}

\section{Introduction}

Production facilities in petrochemical industry are explosive hazardous environments, which requires the use of flameproof electrical equipment, in order to prevent dangerous sparks or energy generated by equipment components in the on-off, load and fault conditions ${ }^{[1]}$, otherwise, once the comprehensive performance of flameproof safety is abnormal during operation, it is likely to generate electrical sparks, electrostatic discharge, mechanical friction sparks and high temperature, which will form ignition source in an explosive environment. Once the leakage of hazardous substances in the upper and lower limits of explosion, it will result in casualties and significant economic losses ${ }^{[2,3]}$. In petrochemical industry, flameproof electrical equipment is the most widely used explosion-proof equipment. There are many accidents caused by explosion-proof equipment in petrochemical sites. According to on-site accident investigation, the direct cause is mostly pressure piling in flameproof enclosure, leading to damages of flameproof enclosure. Pressure piling is defined as the state when an explosive gas mixture in a cavity or interval within an enclosure is ignited, causing the explosive gas mixture in other cavities or intervals connected to it to be precompressed and ignited ${ }^{[4]}$. The relevant standards have made provisions to prevent pressure piling: the internal components of equipment cannot be changed without reassessment, because ignoring changes in conditions can lead to pressure piling, changes in temperature or other similar situations may make the explosion-proof certificate invalid ${ }^{[5]}$. Commonly observed in design and manufacturing of flameproof enclosure, pressure piling is a potential risk of damage to the flameproof enclosure. Specifically, the interconnected structure of flameproof enclosure is most readily exposed to pressure piling. Nevertheless, due to the constraints of equipment and working conditions, many flameproof enclosures have to be designed as connected structures. Hence, the study of explosive properties of flameproof enclosure with interconnected structure under pressure piling has practical engineering significance for the design and installation of flameproof enclosure.

The explosive properties of flameproof enclosure under pressure piling have been thoroughly investigated. However, most studies focused on experiments. For instance, the effects of orifice structure of cylindrical flameproof enclosure on its explosion pressure were investigated ${ }^{[6,7]}$. The results demonstrated that changes in the structure of flameproof products could lead to pressure piling and interconnected structure, so that the explosion pressure increased instantly, flameproof enclosure internal structural changes would significantly change the explosion pressure. Chen et al. ${ }^{[8]}$ investigated the effect of wiring cavity on the explosion pressure of an flameproof motor. Through experimental analysis, the rotation state of the flameproof motor enhanced the turbulence. The turbulence would make the flame deform, increase the contact area of reactants and accelerate the mixing speed of burned gas and unburned gas. Heat conduction and transport rate of reactants were intensified, and then the propagation speed of flame wave along the normal direction and explosion pressure were increased.

\footnotetext{
Corresponding author: ${ }^{a}$ lidong16@cnooc.com.cn; bdsj@hebut.edu.cn

c mengxue@pcec.com.cn
} 
Vishwakarma et al. ${ }^{[9]}$ investigated the effects of double chamber connection structure on maximum explosion pressure Pmax, the maximum rate of pressure rise (dp/dt)ex and explosion index KG. The results demonstrated that the connection of two chambers led to an increase in the contralateral Pmax. The maximum explosion pressure of a flameproof enclosure connected by a pipe of $\varnothing 1.2 \mathrm{~cm}$ was much higher than that of a flameproof enclosure connected by a pipe of $\varnothing 0.3 \mathrm{~cm}$. This was due to the fact that the pipe $(\varnothing=1.2 \mathrm{~cm})$ ignited the compressed gas and air mixture at a higher initial pressure in the opposite pipe than the $\varnothing=0.3 \mathrm{~cm}$ pipe. The maximum pressure rise rate of flameproof enclosures connected with pipes of $\varnothing=0.3 \mathrm{~cm}$ was higher than that of flameproof enclosures connected with pipes of $\varnothing=1.2$ $\mathrm{cm}$. This was due to the rapid combustion of the gas-air mixture of hot combustion products ejected to the opposite side after ignition. All the above studies showed that pressure piling led to significantly increased explosion pressure in flameproof enclosure. Numerical simulation of explosive properties of combustible gas in flameproof enclosure with interconnected structure under pressure piling has rarely been reported.

In this paper, numerical simulation was used to study the characteristics of temperature, pressure and explosion wave propagation in flameproof enclosure with interconnected structure under pressure piling. It provides theoretical guidance for the design of flameproof enclosure with interconnected structure.

\section{Finite element analysis of flameproof enclosure}

\subsection{Physical model}

The flameproof enclosure with a double-chambered connection structure was selected for the study. The explosive properties of flameproof enclosure under pressure piling were investigated. The flameproof enclosure consisted of cylindrical Cavity A, cylindrical Cavity B and round partition with small holes (Material: F304L). The lengths of Cavity A and B were 250 and 500 $\mathrm{mm}$, respectively. The internal diameter of double chambers was $161.5 \mathrm{~mm}$, and the inner diameter of the small hole of the partition was $15 \mathrm{~mm}$. The net volume of Cavity A was about $5.12 \mathrm{~L}$, and the net volume of Cavity B was about 10.23 L. The experimental sample was shown in Fig. 1.

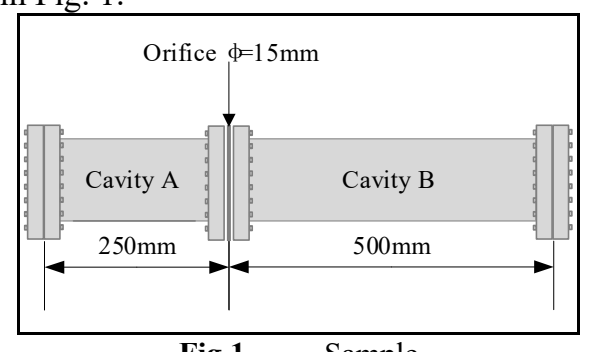

Fig 1. Sample

In this study, SolidWorks was used to establish a 1:1 3D model of flameproof enclosure, and then the model was imported into ICEM for boundary layer meshing, and a finite element analysis model of flameproof enclosure was obtained (see Fig. 2). The numerical solution was performed in FLUENT software. Fig. 3 showed the physical model.

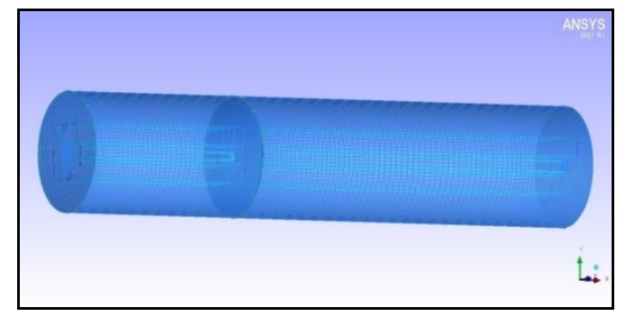

Fig 2. Mesh generation

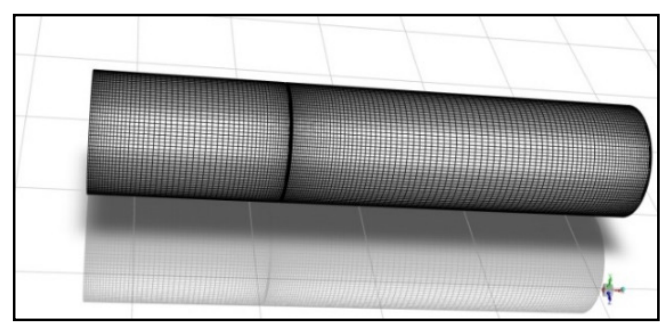

Fig 3. Physical model

\subsection{Numerical calculation}

According to the physical phenomenon of explosion reaction process, combustible gas explosion fluid flow needed to be described by momentum equation, and the velocity field and pressure field distribution were calculated by solving the momentum conservation equation in spatial 3D model. In addition, due to the large temperature difference during the explosion, the effect of radiation on heat transfer must be considered, and the DO discrete coordinate system radiation model which was widely used for explosion reaction was selected. The governing equations used for numerical calculations were the mass conservation equation, the momentum conservation equation, the energy conservation equation, the radiation model equation, the turbulence equation and the component transport and reaction (explosion) model equation.

mass conservation equation:

$$
\frac{\partial \rho}{\partial t}+\nabla \cdot(\rho \vec{v})=S_{m}
$$

momentum conservation equation:

$$
\frac{\partial}{\partial t}(\rho \vec{v})+\nabla \cdot(\rho \overrightarrow{v v})=-\nabla p+\nabla \cdot(\overline{\bar{\tau}})+\rho \vec{g}+\vec{F}
$$

energy conservation equation:

$\frac{\partial}{\partial t}(\rho E)+\nabla \cdot(\vec{v}(\rho E+p))=\nabla \cdot\left(k_{e f f} \nabla T-\sum_{j} h_{j} \vec{J}_{j}+\left(\overline{\bar{\tau}}_{e f f} \cdot \vec{v}\right)\right)+S_{h}$

radiation model equation:

$$
\frac{d I(\vec{r}, \vec{s})}{d s}+\left(\alpha+\sigma_{s}\right) I(\vec{r}, \vec{s})=\alpha n^{2} \frac{\sigma T^{4}}{\pi}+\frac{\sigma_{S}}{4 \pi} \int_{0}^{4 \pi} I(\vec{r}, \vec{s}) \phi\left(\vec{r}, \vec{s}^{\prime}\right) d \Omega^{\prime}
$$

The factors affecting the radiation intensity include absorption, emission, and scattering, which correspond to the second, third, and fourth terms in the equation, respectively. 
$\mathrm{k}-\varepsilon$ turbulence equation is divided into three models, namely the standard k- $\varepsilon$ (SKE) model, RNG k-cmodel and the reality based Realizable (RKE) model, depending on the method of calculating viscosity, the Pr number controlling the turbulent diffusion and the dissipation term. Among these three models, RKE has the widest adaptability and the most accurate calculation.

The reality-based $\mathrm{k}-\varepsilon(R K E)$ turbulence control equation is:

$$
\frac{\partial}{\partial t}(p k)+\frac{\partial}{\partial x_{i}}\left(p k u_{i}\right)-\frac{\partial}{\partial x j}\left[\left(u+\frac{u_{t}}{\sigma_{k}}\right) \frac{\partial k}{\partial x j}\right]=G_{k}-p \varepsilon+S_{\text {near-wall }}
$$

$\frac{\partial}{\partial t}(p \varepsilon)+\frac{\partial}{\partial x_{i}}\left(p \varepsilon u_{i}\right)-\frac{\partial}{\partial x j}\left[\left(u+\frac{u_{t}}{\sigma_{\varepsilon}}\right) \frac{\partial k}{\partial x j}\right]=C_{1 \varepsilon} \frac{\varepsilon}{k} G_{\kappa}-C_{2 \varepsilon} p \frac{\varepsilon^{2}}{k}$

$$
\mu_{t}=\rho C_{\mu} \frac{\kappa^{2}}{\varepsilon}
$$

component transport and reaction model equation:

$$
\frac{\partial}{\partial t}\left(\rho Y_{i}\right)+\nabla \cdot\left(\rho \vec{v} Y_{i}\right)=-\nabla \cdot \overrightarrow{J_{i}}+R_{i}
$$

In order to take into account the influence of diffusion of turbulent components on the reaction, a very accurate conceptual model of eddy dissipation was chosen for the explosion reaction model.

\subsection{Initial conditions}

The test parameters were initialized according to IEC 60079-1, and typical explosive gas ethylene was selected. The volume ratio of the explosive mixture of ethylene and air to air was $8 \pm 5 \%$. The test conditions were shown in Table 1. The ignition source was set at the position shown in Fig. 4. The ignition source temperature was $400 \mathrm{~K}$, and the ignition was performed under the test conditions.

\section{Table1. Initial conditions}

\begin{tabular}{|c|c|c|c|c|c|}
\hline Gas & $\begin{array}{c}\text { Molecular } \\
\text { formula }\end{array}$ & $\begin{array}{c}\text { Volume } \\
\text { ratio }\end{array}$ & $\begin{array}{c}\text { Humidity } \\
(\%)\end{array}$ & $\begin{array}{c}\text { Temperature } \\
\left({ }^{\circ} \mathrm{C}\right)\end{array}$ & $\begin{array}{c}\text { Initial } \\
\text { pressure } \\
\text { (hpa) }\end{array}$ \\
\hline ethylene & $\mathrm{C}_{2} \mathrm{H}_{4}$ & $8 \pm 5 \%$ & $40 \pm 2$ & $20 \pm 5$ & 1024 \\
\hline
\end{tabular}

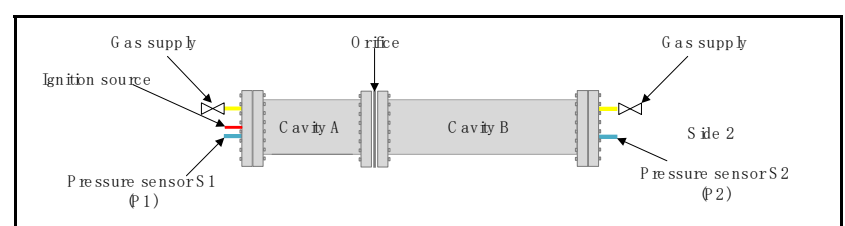

Fig 4. Schematic of testing system

\section{Results and discussion}

\subsection{Temperature field and flame propagation characteristics}

Fig. 5 showed the distribution of temperature field of ethylene explosion process after the ignition of Cavity A. As observed, combustible gas in Cavity A ignited after an ignition energy was applied at the wall of Cavity A. The flame waveform was initially a laminar flame, as the flame propagated forward the flame wavefront was deformed due to the influence of turbulence, the reaction surface increased, and the laminar flame was transformed into a turbulent flame. Since there was no obstacle inside Cavity A, the turbulence was considered to be generated due to the effect of the wall. The maximum temperature of ethylene after explosion reached $2454.68{ }^{\circ} \mathrm{C}$ without considering the leakage. The total duration of the combustion and explosion process in flameproof enclosure with interconnected structure was about $0.13 \mathrm{~s}$. It took $0.0884 \mathrm{~s}$ for the flame to travel from Cavity A (length $=250 \mathrm{~mm}$ ) to the small hole of partition, and $0.0416 \mathrm{~s}$ for cavity B (length $=500 \mathrm{~mm}$ ). At $\mathrm{t}=0.0884 \mathrm{~s}$, the flame reached Cavity B from Cavity A through the small hole in the partition plate in the form of a jet, and ignited Cavity B rapidly. After the burning of Cavity B, the flame was oscillating due to the energy difference between Cavity A and Cavity B, and finally reached equilibrium.

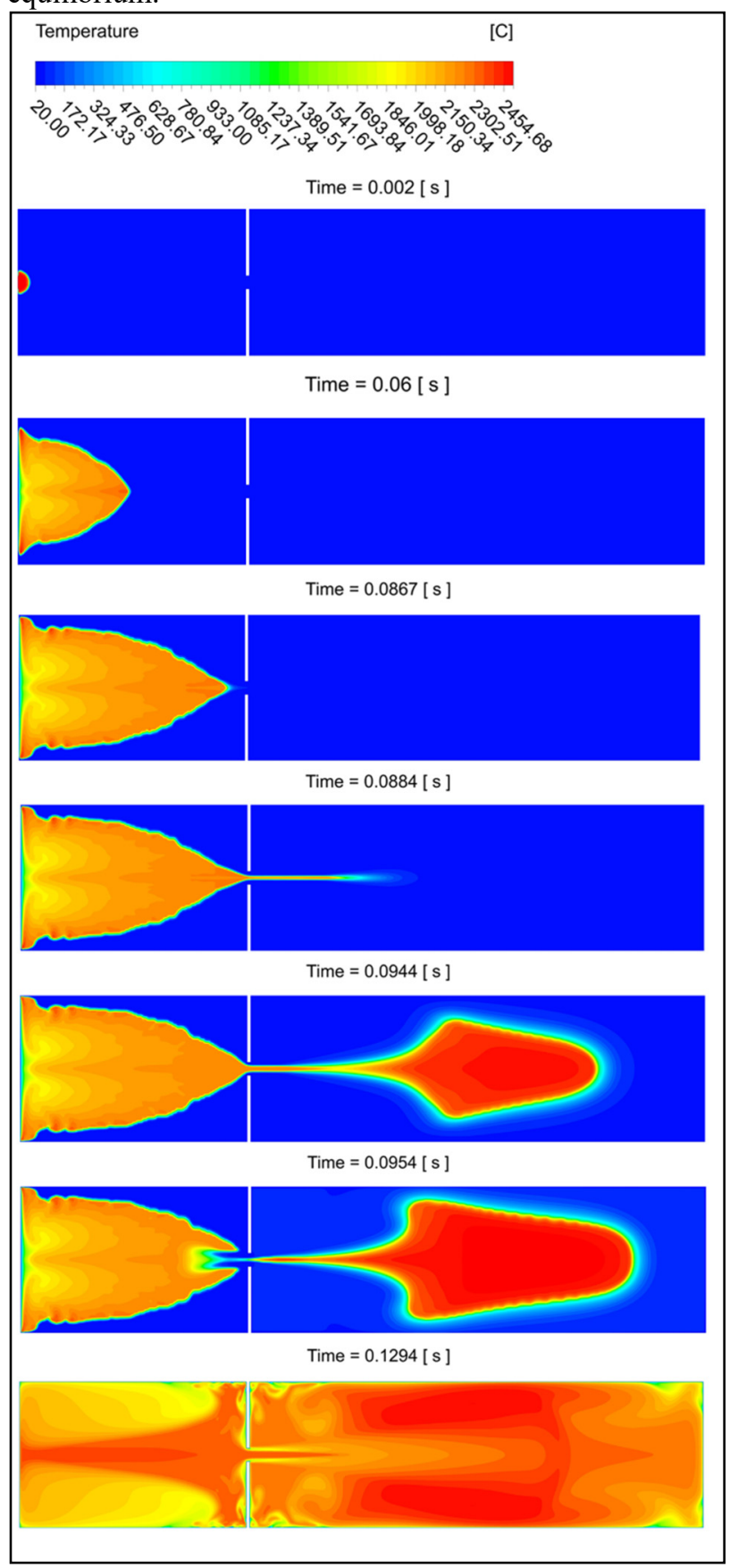

Fig 5. Distribution of temperature field 


\subsection{Velocity field characteristics at the orifice}

Fig. 6 (a) - (f) showed distributions of velocity fields of orifice at the partition for $\mathrm{t}=0.002,0.006,0.0867,0.0884$, 0.0944 and $0.0954 \mathrm{~s}$, respectively. As observed, when the combustible gas was ignited in Cavity $\mathrm{A}$, as the combustible gas burned in Cavity A, the flow rate of combustible gas at the flameproof orifice slowly increased. As shown in Fig. 6 (c), when the flame wave had not reached the partition orifice, the propagation velocity of combustible gas at the orifice was $205.61 \mathrm{~m} / \mathrm{s}$, which was subsonic and smaller than the propagation velocity of explosion pressure wave. As shown in Fig. 6 (d), when the flame wave propagates to the orifice of partition, the velocity reached $567.91 \mathrm{~m} / \mathrm{s}$. This is because the pressure difference between Cavity A and Cavity B had reached the maximum, and the pressure difference increased the flow velocity. The flame spread through the partition orifice. Cavity B was rapidly ignited. Due to the energy difference between the two chambers, the flame was oscillating and finally reached equilibrium.

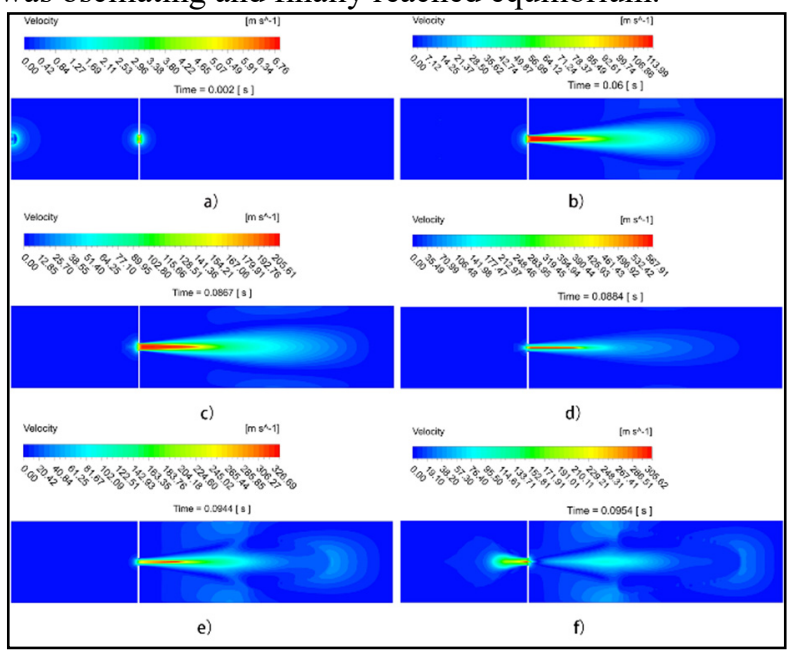

Fig 6. Distribution of velocity field

\subsection{Explosion pressure}

Fig. 7 (a) - (f) illustrated explosion pressure distributions in flameproof enclosure with interconnected structure at $\mathrm{t}$ $=0.002,0.006,0.0867,0.0884,0.0944$ and $0.0954 \mathrm{~s}$, respectively. As shown in Fig. 7 (a) - (d), upon explosion of combustible gas in Cavity A, at the moment of flame propagation from the orifice of the partition to Cavity B, combustible gas in Cavity B was not yet fully combusted, and the pressure in Cavity B was higher than the air pressure, indicating that a pre-pressure was generated. However, the pressure at this stage was always less than the pressure of Cavity A. When the flame traveled to Cavity B in a jet state, it rapidly ignited the combustible gas in Cavity B. As a result, the explosion pressure in Cavity B exceeded the explosion pressure in Cavity A within $0.001 \mathrm{~s}$. Indeed, the ratio of maximum explosion pressure in Cavity B and A exceeded 1.5, as shown in Fig. 7 (d) and (f).

From the perspective of the entire explosion process, increase in explosion pressure in flameproof enclosure under pressure piling was due to the increase in initial pressure. After combustible gas was ignited in one cavity, as it exploded, the explosion pressure wave causes the initial pressure in the other cavity to increase in the equivalent of a constant volume change. The mechanism was consistent with the ideal gas equation of state:

$$
p_{\mathrm{m}}=\frac{T_{\mathrm{m}} n_{m}}{T_{0} \mathrm{n}_{0}} p_{0}
$$

where $\mathrm{p}_{\mathrm{m}}$ is the maximum explosion pressure, $\mathrm{P}_{0}$ is the initial pressure, $\mathrm{T}_{\mathrm{m}}$ is the maximum temperature after explosion, $\mathrm{T}_{0}$ is the initial temperature, $\mathrm{n}_{\mathrm{m}}$ is the moles of gas after explosion, $\mathrm{n}_{0}$ is the moles of gas before explosion.

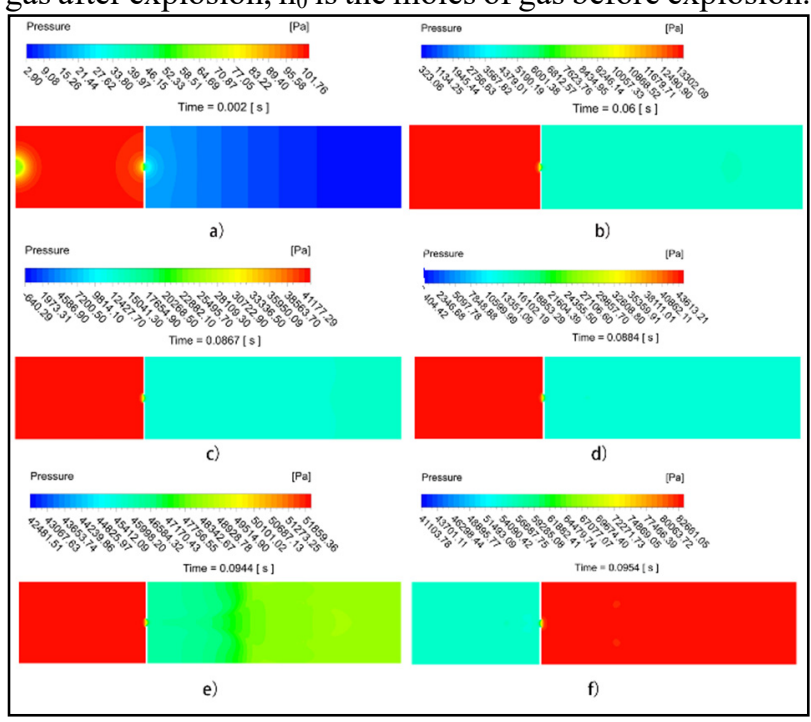

Fig 7. Distribution of explosion pressure field

\subsection{Explosion pressures obtained by simulation}

Fig. 8 showed explosion pressure wave form obtained by numerical simulation. (P1 was pressure collected in Cavity A, P2 was pressure collected in Cavity B).

During the explosion of Cavity A, the pressure in Cavity B increased gradually as the explosion pressure in Cavity A increased. It was greater than atmospheric pressure. Upon ignition of combustible gas in Cavity B, explosion pressure in Cavity A continued to rise, but the slope of the maximum explosion pressure rise was less than Cavitiy B. The explosion pressure in Cavity B rose to the maximum value in an extreme period of time. Eventually, both explosion pressure tends to equalize. The trend Waveform of explosion pressure is consistent with the previous test.

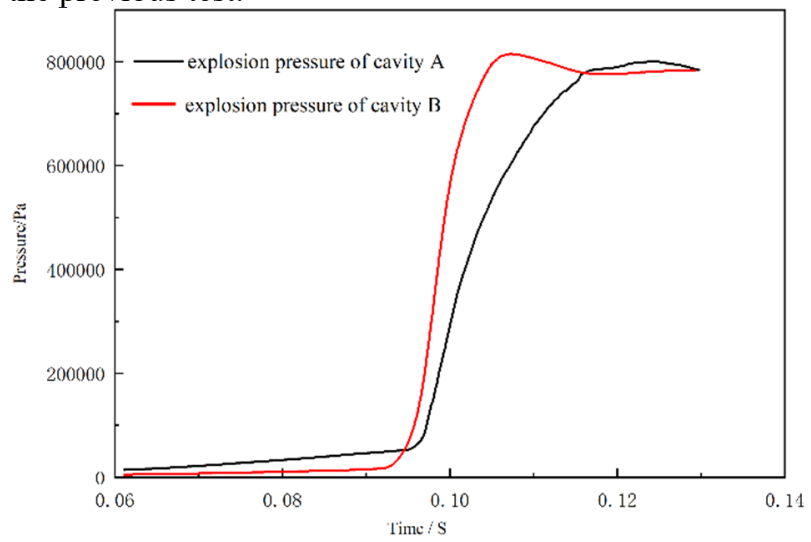

Fig 8. Waveform of explosion pressure 


\section{Conclusions}

Upon ignition of premixed gas in flameproof enclosure with interconnected structure, the initial stage was a laminar premixed flame, which was affected by turbulence during the propagation process, and it will be transformed into a turbulent flame. The burning rate of combustible gas was less than the propagation velocity of the explosion pressure wave. The orifice of the doublecavity interconnection structure caused pre-compression in Cavity B. Under pressure piling, explosion pressure in Cavity B was significantly greater than that in Cavity A, which fully explained the failure of explosion resistance of flameproof enclosure due to pressure piling that made the flameproof enclosure to exceed the design pressure value. Pressure piling mechanism can fully reveal that the steel pipe wiring specified in section 5.4.3 of GB50058 should be isolated and sealed. Due to the steel pipe wiring, the flameproof enclosure forms a double-cavity interconnection structure.

\section{Acknowledgments}

This study is one of the milestones of CNOOC Energy Technology \& Services Limited Talent Program Study on deflagration characteristics of ethylene-air premixed gas in flameproof enclosure (TJY-2020-FB-01).

\section{References}

1. Bozek, Allan.APPLICATION OF IEC 60079-10-1 EDITION 2.0 FOR HAZARDOUS AREA CLASSIFICATION[J].IEEE Transactions on Industry Applications,2017: 1-1.

2. GAO Ruixia. (2020). Control Mode Study on Fire Near Misses in Inflammable and Explosive Units. Journal of Chinese People's Armed Police Force Academyv.36; No. (10), 32-35

3. IEC60050-426(2020) Internationnal Electrotechnical Vocabulary(IEV)-Part 426:Explosive atmospheres, Edition3.0, 22.

4. IEC 60079-14(2013),Explosive Atmospheres - Part 14 : Electrical installations design, selection and erection International Electrotechnical Commision, Edition5.0, 69-70.

5. JU Zhe, CHEN Fandong, HE Zhenguo, SHI Lei, \& LI Bing. (2014). The Superposition Impact of Orifice Structure of Flameproof Enclosure on Explosion Pressure. Safety in Coal Mines, v.45;No. (05), 219221

6. ZHANG Jinhui, \& CHEN Zhiming. (2019). Experimental study on explosion pressure testing for cylindrical flameproof products. Journal of Safety Science and Technology, v.15; No. (05), 80-84

7. CHEN Fandong. (2019). Effect of Termination Compartment on Explosion Pressure of Flameproof Motor. Safety in coal Mines, v.50;No. (10), 129-131

8. Zhen, Yaya, Wang, Zhirong, Gong, \& Junhui. (2018). Experimental study of the initial pressure effect on methane-air explosions in linked vessels. Process Safety Progress.

9. Vishwakarma, R. K. , Ranjan, V. , \& Kumar, J. . (2015). Dynamic response and effect of apertures on explosion parameters of flameproof apparatus. Journal of Loss Prevention in the Process Industries, $33,245-249$. 